\title{
NEMATOSIT DARI TIGA SPESIES KARANG SCLERACTINIA, GENUS POCILLOPORA
}

\author{
(Nematocysts of three Scleractinian corals of genus Pocillopora)
}

\author{
Carolus P Paruntu, Husen Rifai dan Janny D Kusen \\ Fakultas Perikanan dan Ilmu Kelautan Universitas Sam Ratulangi, Manado, Sulawesi Utara
}

\begin{abstract}
Nematosit dari tiga spesies karang Scleractinia, yaitu Pocillopora eydouxi, Pocillopora woodjonesi dan Pocillopora verrucosa yang mendiami terumbu karang di kawasan Pantai Malalayang, Manado, Provinsi Sulawesi Utara diteliti dalam penelitian ini. Dari 25 tipe nematosit utama yang dikenal dalam filum Cnidaria, dua tipe di antaranya dijumpai pada ketiga spesies ini. Dua tipe utama nematosit, yaitu holotrichous isorhizas (HI) dan microbasic p-mastigophores (MpM) teramati pada P. eydouxi dan P. woodfonesi, dan hanya satu tipe, yaitu microbasic p-mastigophore $(M p M)$ diamati pada $P$. verrucosa. Komposisi nematosit pada $P$. eydouxi serupa dengan $P$. woodjonesi, tetapi sangat berbeda dari $P$. verrucosa. Ukuran Hh adalah berbeda antara $P$. eydouxi dan $P$. woodjonesi, dan juga ukuran MpM berbeda antara $P$. verrucosa dan $P$. eydouxi atau $P$. woodjonesi. Hasil pengamatan menunjukkan bahwa komposisi dan dimensi nematosit cenderung bervariasi di antara ketiga spesies ini, walaupun berada dalam satu genus. Perbedaan-perbedaan dalam nematosit ini diusulkan untuk dapat digunakan dalam klasifikasi karang.
\end{abstract}

Kata kunci: Pocillopora eydouxi, Pocillopora woodjonesi, Pocillopora yerrucosa, nematosit, holotrichous isorhizas (HI), microbasic p- mastigophore (MpM).

Nematocysts of three Scleractinian corals, i.e., Pocillopora endouxi, Pocillopora woodjonesi and Pocillopora verrucosa occurring in the reef of the coastal area of Malalayang, Manado, North Sulawesi Province were studied. Of the 25 major types of nematocysts recognized in the phylum of Cnidaria, two types were encountered in these three corals. Two major types of holotrichous isorhizas (HI) and microbasic pmastigophores (MpM) were observed in P. eydouxi and P. yoodjonesi, and only one type of microbasic pmastigophore (MpM) was observed in $P$. verrucosa. The nematocyst composition of $P$. eydouxi was similar to that of $P$. woodjonesi, but markedly different from that of $P$. verrucosa. The size of HI was different between $P$. eydouxi and $P$. woodjonesi, and also the size of MpM was different between $P$. verrucosa and $P$. eydouxi or $P$. woodjonesi. The present obseryation showed that nematocyst composition and dimension might be varied among these three corals. It is suggested that the differences in the nematocysts could be used in the classification of corals.

Keywords: Pocillopora eydotuxi, Pocillopora woodjonesi, Pocillopora verrucosa, nematocysts, holotrichous isorhizas (HI), microbasic p-mastigophore (MpM).

\section{PENDAHUIUAN}

Filum Cnidaria me̊miliki organ intraselular yang unik dalam jaringan tubuh ektoderemnya, yaitu cnidae yang akán dilepaskan keluar tubuhnya jika ada rangsangan dari lingkungan dimana fauna ini tinggal. Crridae digunakan untuk menangkap mangsa melawan predator, menyerang Cnidaria lainnya yang berada di sekitarnya, atau untuk melekatkan tubuhnya pada substrat yang cocok selama proses setelmen (Watson dan Wood 1988; Fautin 2009). Cnidae ini, terkandung dalam sebuah sel yang disebut cnidocyte. Cnidae dibagi ke dalam tiga kategori utama, yaitu nematosit, spirosit dan ptikosit (Mariscal 1984; Watson dan Wood 1988). Nematosit terdapat di seluruh anggota filum Cnidaria, sedangkan spirosit dan ptikosit hanya dibatasi pada beberapa anggota ini (Fautin 2009).
Tipe-tipe nematosit yang berbeda umumnya sudah dianggap sebagai salah satu karakter yang berguna dalam taksonomi dari perbedaan ordo-ordo Cnidaria (Pires dan Pitombo 1992). Fautin menyatakan bahwa salah satu masalah dalam penggunaan sel nematosit untuk taksonomi karang adalah komposisi nematosit berbeda di antara organorgan tubuh yang berbeda tergantung pada fasefase pertumbuhan atau kondisi fisiologisnya. Tentakel memiliki komposisi nematosit yang berbeda dari pada mesenterial filamen atau bagian-bagian tubuh polip yang lain (Schmidt 1974; Thomason dan Brown 1986; Song 1988). Tentakel-tentakel penyapu dari polip sudah dianggap sebagai organorgan agresif dari karang, yang memiliki komposisi nematosit berbeda dari pada tentakel-tentakel biasa dari polip (den Hartog 1977; Hidaka dan Yamazato 1984; Hidaka et al. 1987; Peach dan Guldberg 
1999). Paruntu (1996) dan Paruntu et al. (2000) telah memperlihatkan bahwa komposisi cnidae berubah selama fase-fase perkembangannya, yaitu mulai dari fase planulae sampai pada polip dewasa dari Pocillopora damicornis. Planulae Pocillopora damicornis mempunyai tipe holotrichous isorhizas (HI) besar yang mana itu tidak hadir pada polip dewasa (Hidaka 1991; Paruntu 1996, Paruntu et al. 2000).

Perbedaan komposisi dan dimensi nematosit pada empat spesies karang Scleractinia, baik pada spesies-spesies karang dalam satu genus maupun yang berbeda genus sudah diteliti oleh Wafar (1974). Selanjutnya Wafar (1974) mengusulkan bahwa perbedaan-perbedaan nematosit dapat digunakan untuk klasifikasi karang. Wewengkang et.al. (2007) memperlihatkan bahwa perbedaan komposisi nematosit dari perbedaan morfotipe $\mathrm{H}$ dan S serta perpaduan komposisi nematosit dalam morfotipe M dari Galaxea fascicularis dan tetap mengusulkan bahwa perbedaan morfotipe dari G. fascicularis hanya dipengaruhi oleh faktor lingkungan dan mereka masih merupakan spesies yang sama. Pada studi pendahuluan, peneliti menemukan komposisi nematosit dari $P$. eydouxi berbeda dari $P$. damicornis yang ditemukan oleh Paruntu (1996) dan Paruntu et al. (2000). Terdapat sekitar 25-30 tipe nematosit utama yang sudah diperkenalkan dalam filum Cnidaria (Weill 1930, 1934a,b; Mariscal 1974; Fautin 2009). Studi sekarang in akan meneliti tentang tipe, komposisi dan dimensi nematosit dan membandingkanya di antara tiga spesies karang Scleractinia, yaitu $P$ ? eydouxi, $P$. woodjonesi dan $P$. verrucosa.

Tujuan penelitian ini adalab untuk menyediakan informasi tentang tipe, komposisi dan dimensi nematosit dan membandingkannya dengan tiga spesies karang Scleractinia, yaitu $P$. eydouxi, P. woodjonesi dan P. yerrucosa.

\section{BAHAN DANMETODE PENELITIAN}

Kolon karang $P$. eydouxi, $P$. woodjonesi dan $P$. Kerrucosa dikumpulkan dari terumbu karang di Pantai Malalayang, Kota Manado, Provinsi Sulawesi Utara pada tahun 2013. Setiap jenis karang yang diuji diambil tiga koloni dengan ukuran diameter sekitar $5 \mathrm{~cm}$ dan diawetkan ke dalam $10 \%$ formalin dalam air laut. Selanjutnya, kolonikoloni karang tersebut didekalsifikasi ke dalam campuran larutan $10 \%$ formalin dan $10 \%$ asam asetat dalam air tawar dengan perbandingan 1:1 selama tiga hari untuk memperoleh jaringan tubuh yang lunak tanpa skeleton. Kemudian, sampelsampel yang telah didekalsifikasi disimpan dalam larutan formalin $10 \%$ dalam air tawar sampai itu digunakan.

Sampel-sampel yang telah didekalsifikasi diletakkan di atas slide glass dan dilumatkan di bawah cover glass, kemudian nematosit diamati dan diambil foto-foto di bawah sebuah mikroskop tipe phase contrast microscope (Olympus CX41RF) dengan pembesaran 400X. Panjang dan lebar kapsul dan panjang tangkai dari nematosit yang dalam keadaan belum melepaskan tangkai dan benangnya dari kapsul (undischarged nematocysts) diukur di atas cetakan-cetakan foto yang diambil dengan menggunakan jangka sorong tipe manúal. Pánjang tangkai dari MpMs (undischarged nematocysts) diukur dari sebuah jarak antara ujung nematosit yang satu sampai pada ujung tangkainya yang berbentuk V. Dimensi nematosit diukur pada tipetipe nematosit yang utama saja, sedangkan tipe nematosit minor diabaikgn, karena sulit diidentifikasi dan dihitung. Jumlah setiap tipe nematosit dihitung pada pating sédikit 5 cetakan foto yang diambil dari setiap sampel dan dihitung dalam setiap sampek koloni dari setiap spesies karang yang diuj

- Pengujian statistik dilakukan pada komposisi dan dimensi nematosit dengan menggunakan analisis uji-t (t-student) untuk menguji perbedaan 2 rataan dari populasi-populasi dan uji-ANOVA satu arah untuk menguji perbedaan 3 rataan dari populasi-populasi. Setelah uji-ANOVA satu arah, dilanjutkan dengan uji-Tukey untuk mendeteksi populasi-populasi yang berbeda nyata dan yang tidak berbeda nyata. Untuk komposisi nematosit, uji statistik dilakukan setelah data dalam satuan persen ditransformasi ke arcsine. Nilai signifikansi yang digunakan $(\mathrm{P})$ adalah 0,05 .

\section{HASIL PENELITIAN}

Pocillopora eydouxi dan P. woodjonesi memiliki dua tipe nematosit utama, yaitu holotrichous isorhizas (HI) dan microbasic p-mastigophore (MpM) (Gambar 1A dan 1B), sedangkan Pocillopora verrucosa hanya memiliki satu tipe nematosit utama, yaitu microbasic p-mastigophore (MpM) (Gambar 1C).

HI mempunyai benang dengan duri yang berkembang baik dan diameter benang relatif sama, tetapi tidak memiliki tangkai, sedangkan MpM memiliki sebuah tangkai dengan duri-duri yang panjangnya sekitar dua per tiga dari panjang kapsul dan ujung tangkainya membentuk seperti huruf V, serta memiliki benang (Mariscal 1974; Ostman 2000). 
Komposisi nematosit dari P. eydouxi adalah serupa dengan $\mathrm{P}$. woodjonesi, tetapi itu berbeda dari P. verrucosa (Gambar 2A, 2B, 2C). Tipe HI dan $\mathrm{MpM}$, keduanya sama berlimpah pada $\mathrm{P}$. eydouxi dan P. woodjonesi, tetapi HI tidak hadir pada P. verrucosa dan hanya tipe MpM saja yang ditemukan dan sangat berlimpah pada P. verrucosa. Data persen memperlihatkan bahwa tidak ada perbedaan yang nyata dalam kelimpahan tipe HI antara P. eydouxi dan P. woodjonesi (Uji-t, $\mathrm{P}>0.05$ ). Selanjutnya, data memperlihatkan bahwa ada perbedaan yang nyata dalam kelimpahan tipe MpM di antara $\mathrm{P}$. eydouxi, P. woodjonesi dan P. verrucosa (UjiANOVA satu arah, $\mathrm{P}<0.05)$. Hasil uji lanjut, yaitu uji-Tukey memperlihatkan bahwa komposisi MpM pada P. verrucosa berbeda secara signifikan dari P. eydouxi atau P. woodjonesi.

HI yang ditemukan pada Pocillopora eydouxi adalah lebih besar dibandingkan dengan yang ada pada P. woodjonesi (Uji-t, $\mathrm{P}<0.05$; Tabel 1). Selanjutnya, $\mathrm{MpM}$ yang ditemukan pada ke tiga jenis karang, yaitu Pocillopora eydouxi, P. woodjonesi dan P. verrucosa memperlihatkan ukuran yang berbeda nyata (uji-ANOVA satu arah, $\mathrm{P}<0.05$; Tabel 1). Hasil uji lanjut, yaitu uji-Tukey
memperlihatkan bahwa MpM pada P. verrucosa memperlihatkan bahwa MpM pada $\mathrm{P}$. verrucosa
memiliki ukuran nematosit yang lebih besar dibandingkan dengan ukuran MpM pada $\mathrm{P}$. eydouxi dan P. woodjonesi.

\section{PEMBAHASAX}

Komposisi nematosit berbeda nyata antara P. eydouxi atau P. yoodjonesi dan P. verrucosa. HI hadin dalam jaringan tubuh $P$. eydouxi dan P. woodjonesi, tetapi sama sekali tidak hadir dalam jaringan tubuh P. verrucosa, sedangkan MpNG hadir di antara ke tiga spesies yang diuji. Komposisi dan dimensi nematosit boleh bervariasi di antara tiga spesies yang diuji ini, owalaupun berada dalam satu genus. Itu diusulkan bahwa perbedaan-perbedaan dalam nematosit dapat digunakan untuk klasifikasi karang.

Paruntu et.al. (2000) mengusulkan bahwa HI digunakan oleh planulae Pocillopora damicornis untuk pertahanan melawan predator pada fase-fase awal perkembangan dan juga itu memungkinkan sebagai nematosit spesifik untuk planula yang berfungsi menangkap makanan. Den Hartog (1977) sudah menemukan bahwa holotrichous sebagai alat penyerang yang menyebabkan nekrosis pada jaringan tubuh dari kompetitor yang diserang. Dalam studi ini, HI hadir dalam jaringan tubuh $\mathrm{P}$. eydouxi dan P. woodjonesi dan itu mungkin digunakan sebagai pertahanan melawan predator dan menangkap makanan. Selanjutnya, dalam studi sekarang ini MpM hadir dalam ke tiga jaringan tubuh karang yang diuji, yaitu $\mathrm{P}$. eydouxi, P. woodjonesi dan P. verrucosa. Paruntu (1996) dan Paruntu et.al. (2000) memperlihatkan MpM hadir secara kpnsisten sejak dari fase planulae, polip muda sampai pada polip-polip dewasa, dan menyarankan bahwa MpM merupakan nematosit /spesifik pada genus Pocillopora atau paling tidak hadir pada spesies-spesies yang telah diuji dan disebutkan sekarang ini. Paruntu (1997) mengusulkan bahwa MpM yang berasal dari mesenterial filament dari Pachyseris rugosa merupakan nematosit yang digunakan untuk pencernaan mangsa dan pertahanan. Nematosit $\mathrm{MpM}$ umumnya dianggap sebagai alat penangkap mangsa melalui penetrasi dan pertahanan (Mariscal 1974). Studi sekarang ini memperlikatkan bahwa kehadiran MpM dalam ke tiga spesies yang diuji, yaitu P. eydouxi, P. moodjonesi dan P. verrucosa mungkin digunakan sebagai alat untuk pencernaan mangsa dan pertahanan.

Ukuran-ukuran dari tipe nematosit yang sama antara spesies-spesies yang diuji adalah berbeda nyata (Table 1). Ini menunjukkan bahwa ukuran-ukuran dari tipe nematosit yang sama kemungkinan besar dipengaruhi oleh perbedaan spesies-spesies karang, walaupun masih dalam satu genus Pocillopora. Hidaka (1992) memperlihatkan bahwa morfologi nematosit berhubungan erat dengan morfologi skeleton dari karang.

Studi sekarang ini memperlihatkan bahwa komposisi nematosit antara P. eydouxi dan P. woodjonesi adalah serupa, tetapi itu berbeda dari P. verrucosa. Tipe HI hadir dalam jaringan tubuh P. eydouxi dan P. woodjonesi, tetapi tidak hadir dalam $P$. verrucosa, sedangkan MpM merupakan nematosit spesifik untuk genus Pocillopora atau paling tidak hadir pada ke tiga spesies yang diuji. Selanjutnya, ukuran-ukuran dari tipe nematosit yang sama antara spesies-spesies yang diuji adalah berbeda nyata. Perbedaan-perbedaan komposisi dan dimensi nematosit boleh bervariasi di antara tiga spesies yang diuji ini, walaupun berada dalam satu genus. Itu diusulkan bahwa 
perbedaan-perbedaan dalam nematosit dapat digunakan untuk klasifikasi karang.

\section{UCAPAN TERIMA KASIH}

Ucapan terima kasih secara khusus disampaikan kepada Prof. Michio Hidaka dari Ryukyu University Japan atas ide-ide yang inspiratif dan bimbingannya dalam penelitianpenelitian nematosit karang. Ucapan terima kasih juga disampaikan kepada Dekan FPIK Unsrat Manado yang sudah memfasilitasi penulis dalam penyelesaian penelitian ini, dan kepada Prof. Farnis Boneka, Ir. Sammy Longdong, M.Si. dan Ir. Hermanto Manengkey, M.Si. dari Unsrat Manado atas masukkan dan kritikan yang membangun dalam penelitian ini.

\section{DAFTAR PUSTAKA}

Fautin DG. 1988. Importance of nematocyst to actinian taxonomy. Hal. 487-500. In Hessinger, D.A. and H.M. Lenhoff (eds). The biology of nematocyst. Academy Press. Inc. San Diego.

Fautin DG. 2009. Structural diversity, systematics, and evolution of cnidae. Toxicon 54: 1054-1064. 11 hal.

Hartog JC. den. 1977. The marginal tentacles of Rhodactis sanctithomae (Corallimorpharia) and the sweeper tentacles of Montrastrea cavernosa (Scleractinia) their cnidom and possible function. Proc. 3rd Int. Coral Reef Symp. 1 : 463469.

Hidaka K. 1991. Use of cnida morphology in taxonomy of corals. Graduation thesis, University of the Ryukyus, (in Japanese).

Hidaka M. dan Yamazato K. 1984. Intraspecificinteractions in a scleractinian coral, Galaxea fascicularis - induced formation of sweeper tentacles. Coral Reefs, 3(2), 77 - 85.

Hidaka M., Miyazaki I. dan Yamazato K 1987. Nematocysts characteristic of the sweeper tentacles of a scleractinian coral, Galaxea fascicularis (Linnaeus). Galaxea, $6: 195$ 207.

Hidaka M. 1992. Use of nematocyst morphology for taxonomy of some related species of Scleractinian Corals. Galaxea, $11: 21+28$

Mariscal RN. 1974. Nematocyst. in Muscatine, L. and H. M. Lenhoff (eds). Coelenterates biology : reviews and new perspective.Academy Press. New York. Hal. 129-178.

Mariscal RN. 1984. Cnidaria : Cnidae. in Bereiter-Hahn J, Matoltsy AG, Richards KS (eds) Biology of the Integument, Vol. 1. Invertebrates. Springer, Berlin Heidelberg New York, pp 57-68.

Ostman C. 2000. A guideline to nematocysts nomenclature and classification, and some notes on the systematic value of nematocysts. Scientia Marina, 64 (Supl. 1): 31-46. 16 hal.

Paruntu CP. 1996. Studies on cnidae of scleractinian corals: Developmental changes in cnida composition and spatial distribution of cnidae along mesenterial filaments. Master thesis. University of Ryukyus Okinawa Japan. Hal. 1-58 dan 1-36.

Paruntu CP. 1997. Spatial distribution of cnidae along mesenterial filaments of Pachyseris rugosa. Berita Fakultas Perikanan. UNSRAT. 5 (1-2).

Paruntu CP., Hidaka K., Hidaka M. 2000. Developmental changes in cnidae composition of the coral Pocillopora damicornis. Galaxea, JCRS. Japan. 2 : 23-28.

Peach MB dan Hoegh-Guldberg O. 1999. Sweeper polyps of the coral Goniopora tenuidens (Scleractinia: Poritidae). Invertebrate Biology 118: 1-7.

Pires DO dan Pitombo FB. 1992. Cnidae Of The Brazilian Mussidae (Cnidaria : Scleractinia) and Their Value In Taxonomy. Bull. of Mar. Sci. 511(2): 231-244.

Schmidt H. 1974. An evolutionin the Anthozoa. Proc. 2nd Int. Coral Reef Symp., 1 : 533-560.

Song. 1988. A systematic study on the Korean Anthozoa. 11. Cnidae of scleractinia. Korean J. Syst. Zool. Special Issue $2: 25-36$.

Thomason JC dan Brown BE. 1986. The cnidom : an index of Aggressive proficienly in scleractinian corals. Coral Reef, $5: 93-10$

Wąár MVM. 1974. Nematocysts in four species of corals. Mahasagar, Vol. 7, Nos. 1 \& 2.5 hal.

Watanabe T., Nishida M., Watanabe K., Wewengkang DS. dan Hidaka M. 2005. Polymorphism in nucleotide sequence of mitochondrial intergenic region in Scleractinian Coral (Galaxea fascicularis). Marine Biotechnology, Vol. 7: 33-39. 7 hal.

Watson GM. dan Wood RL. 1988. Colloqioum on terminology. Hal. 21-23. In : Hessinger, D.A. and H.M. Lenhoff (eds). The biology of nematocyst, Academic Press Inc. San Diego.

Weill R. 1930. Essai d'une classification des ne'matocystes des cnidaires.Bulletin Biologique de la France et de la Belgique 64, 141-153.

Weill R. 1934a. Contribution a l'e'tude des cnidaires et de leurs ne'matocystes. I. Recherches sur les ne'matocystes. Travaux de la Station Zoologique de Wimereux 10, 1-347.

Weill R. 1934b. Contribution a l'e'tude des cnidaires et de leurs ne'matocystes. II. Valeur taxonomique du cnidome. Travaux de la StationZoologique de Wimereux 11, 348700 .

Wewengkang D., Watanabe T. dan Hidaka M. 2007. Studies on morphotypes of the coral Galaxea fascicularis from Okinawa: polyp color, nematocyst shape, and coenesteum density. Galaxea, JCSR, 9: 49-59. 11 hal. 
A.

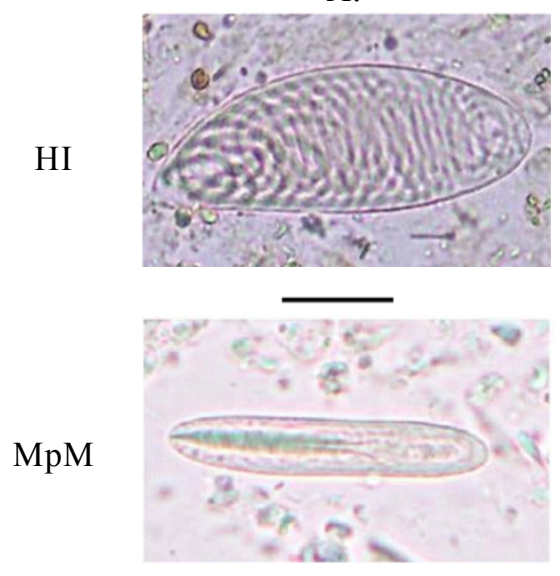

B.
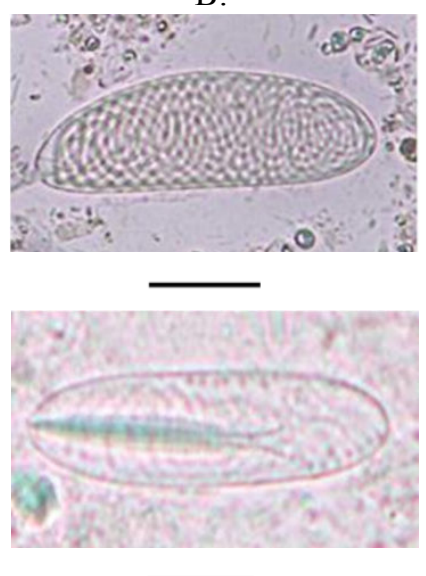

C.

Gambar 1. (A) Nematosit dari P. eydouxi. (B) Nematosit dari Pocillopora woodjonesi. (C) Nematosit dari Pocillopora verrucosa. (HI) holotrichous isorhiza; (MpM) Microbasic p-mastigophore. Skala bar: $10 \mu \mathrm{m}$.

Figure 1. (A) Nematosit from P. eydouxi. (B) Nematosit from Pocillopora wobdjonesi. (C) Nematosit from Pocillopora verrucosa. (HI) holotrichous isorhiza; (MpM) Microbasic p-mastigophore. Bar line: $10 \mu \mathrm{m}$.
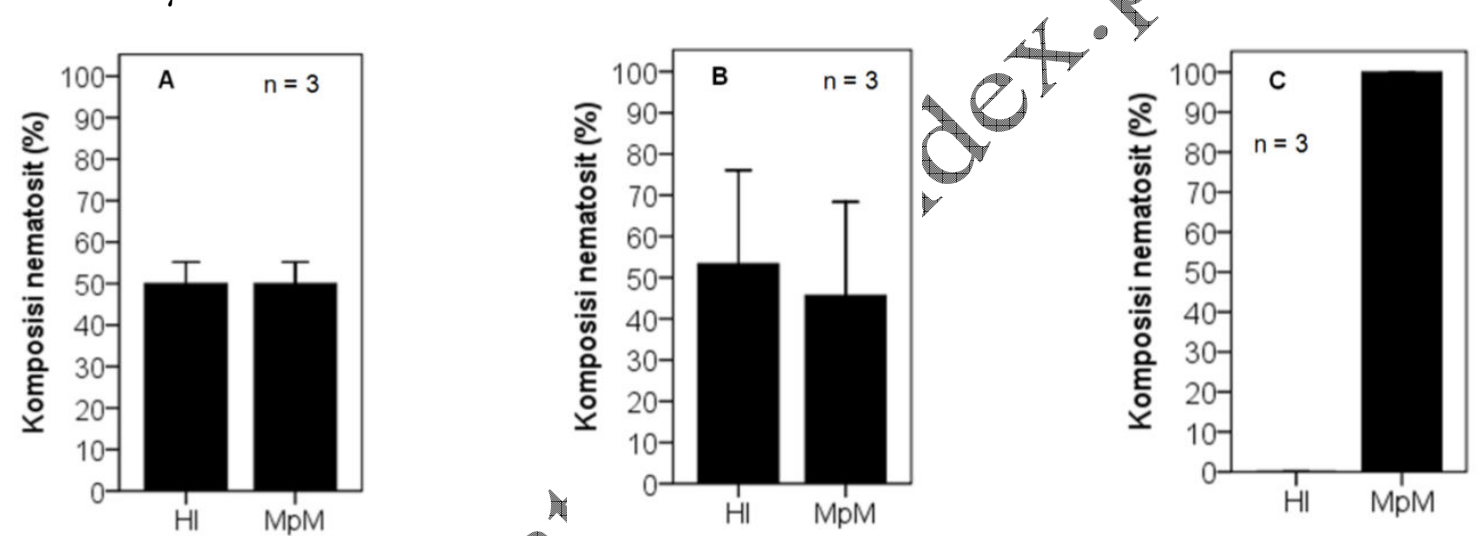

Gambar 2. (A) Komposisi nematosit dâi $\bar{P}$. eydouxi, (B) Komposisi nematosit dari P. woodjonesi, (C) Komposisi nematosit dari $P$. verrucosa. Nilai rata-rata persen \pm SD ditampilkan. $n$ adalah jumlah sampel koloni dari setiapspessies yang diuji.

Figure 2. (A) Nematosit composition of P. eydouxi, (B) Nematosit composition of $P$. woodjonesi, (C) nematosit

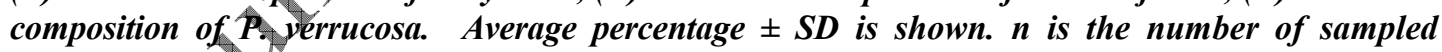
colonies of each species.

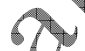

Tabel 1. Dimensimematosit (undischarged nematocysts) dari $P$. eydouxi, $P$. woodjonesi dan $P$. verrucosa.

Table 1. Dimenision of nematocyts (undischarged nematocysts) from $P$. eydouxi, $P$. woodjonesi and $P$. verrucosa.

\begin{tabular}{|c|c|c|c|c|}
\hline & Jenis karang & $\begin{array}{c}\text { Panjang kapsul } \\
(\mu \mathrm{m})\end{array}$ & $\begin{array}{l}\text { Lebar kapsul } \\
(\mu \mathrm{m})\end{array}$ & $\begin{array}{c}\text { Panjang tangkai } \\
(\mu \mathrm{m})\end{array}$ \\
\hline & Pocillopora eydouxi & $28,75 \pm 2,36(3)$ & $10,19 \pm 0,84(3)$ & \\
\hline & Pocillopora woodjonesi & $25,67 \pm 3,34(3)^{*} \quad \mid$ & $9,33 \pm 1,93(3)^{*}$ & \\
\hline \multirow[t]{3}{*}{ МрМ } & Pocillopora eydouxi & $27,25 \pm 4,51(3)$ & $7,00 \pm 1,69(3)$ & $16,691 \pm 3,25(3)$ \\
\hline & Pocillopora woodjonesi & $26,88 \pm 4,65(3)$ & $7,60 \pm 1,54(3)$ & $17,31 \pm 3,39(3)$ \\
\hline & Pocillopora verrucosa & $35,25 \pm 8,03(3)^{* * *}$ & $8,66 \pm 2,02(3)^{*}$ & $21,81 \pm 6,73(3)^{*}$ \\
\hline
\end{tabular}

Keterangan: Jumlah dalam tanda kurung adalah jumlah sampel koloni yang diukur dari masing-masing jenis karang yang diuji. Paling sedikit lima nematosit diukur dari setiap sampel koloni dari masing-masing jenis karang yang diuji untuk menghitung nilai rata-ratanya. Tanda bintang menunjukkan nilai-nilai adalah berbeda antara jenis-jenis karang yang diuji (Uji-t untuk HI dan Uji-Tukey untuk MpM, $* \mathrm{P}<0.05$, $* * * \mathrm{P}<0,001$ ). Nilai-nilai yang tidak berbeda nyata pada tingkat $\mathrm{P}>0.05$ ditunjukkan oleh sebuah garis vertikal. 